Article

\title{
Asymmetric Dependence between Oil Prices and Maritime Freight Rates: A Time-Varying Copula Approach
}

\author{
Ki-Hong Choi ${ }^{1}$ and Seong-Min Yoon ${ }^{2, *}$ \\ 1 Institute of Economics and International Trade, Pusan National University, Busan 46241, Korea; \\ stoltz@nate.com \\ 2 Department of Economics, Pusan National University, Busan 46241, Korea \\ * Correspondence: smyoon@pusan.ac.kr; Tel.: +82-51-510-2557
}

Received: 14 November 2020; Accepted: 18 December 2020; Published: 21 December 2020

\begin{abstract}
Changes in crude oil price affect the shipping freight market via three different channels. This study explores the dependence structure between oil prices and maritime freight rates to identify the effective channel. Therefore, it investigates the relationship between oil prices and three major maritime freight rates; the Baltic Dry Index (BDI), the Baltic Dirty Tanker Index (BDTI), and the Baltic Clean Tanker Index (BCTI). We employ the decomposition method, not studied in the existing literature, and the copula approach which can identify the time-varying effects and asymmetry in the tail dependence structure between oil prices and freight rates. The main results of this analysis are as follows: the decomposed components display different conditional dependence patterns, and asymmetry is revealed in the upper and lower tail dependence. In the long-run, we find more dependence in extreme periods like the financial crises. In short-run fluctuations, we find the dependence increases in an economic boom. The implications of the results suggest that dependence can vary over time and may change depending on extreme events, implying that the complementary strategies should be different the long-run and short-run.
\end{abstract}

Keywords: oil price; maritime freight rate; asymmetry; dependence; copula; decomposition

\section{Introduction}

Recently, over $80 \%$ of the global goods trade is conveyed by sea using maritime transport [1]. Maritime transportation is known to be the most efficient and cost-effective way to transport goods in large quantities. Since the 1960s, containerization has greatly cut down the costs of international trade of commercial goods and increased its speed [2].

Although the global seaborne trade volume recorded an annual average increase of $2.95 \%$ over the last decade, from 8230 million tons in 2008 to 11,005 million tons in 2018, the global shipping capacity showed an annual average increase of $5.66 \%$ in the same period, from 1118 million DWTs in 2008 to 1938 million DWTs in 2018 [3]. This resulted in persistent global overcapacity in the shipping freight markets. Due to weak demand and overcapacity in maritime transport, low freight rates have been observed continuously in recent years, resulting in significant challenges for shipping companies in their business conditions and decision-making.

Theoretically, crude oil price changes affect the shipping freight market via three channels. The first channel is related to shipping companies' transportation costs. According to Lyridis and Zacharioudakis [4], transportation costs in the shipping freight market can be classified as capital costs, running costs, and voyage costs. Voyage costs may vary, depending on the voyage distance and the selected route. The study also considered fuel costs, tugging, and port and canal costs. For a 
company in the freight market, bunker fuel is a considerable cost, which as a product of crude oil is linked to oil price. The shipping industry is highly affected by fuel prices. Bunker fuel is one of the largest operating expenses of any shipowner, accounting for almost $50 \%$ of voyage costs, an even greater amount than crew wages [5]. As bunker (fuel oil) prices are highly connected to crude oil prices, an unanticipated increase in oil prices inevitably increases costs and worsens the shipowners' profitability. In this channel, oil price moves in the same direction as the freight rate.

The second channel is related to crude oil demand due to global economic fluctuation. If there is an increase in economic activity in the global economy, more energy is used, and the demand and price of oil will increase. The shipping industry is highly connected to international trade. Therefore, it is highly sensitive to fluctuations in the global consumption and production of commercial goods and raw materials which are separate in location. If the maritime freight volume increases, the freight rate will increase simultaneously. Shipowners may charge a higher freight rate to recompense the increased fuel expense of their vessels. Therefore, the oil price and freight rates comove due to global economic fluctuations.

Finally, the third channel is related to crude oil transport services due to oil supply shocks. Oil prices directly affect global oil transportation operation, mainly served by ocean tankers. If crude oil supply reduces unexpectedly, the volume of crude oil transport services decreases, and the freight rate of oil tankers decreases. In this case, oil price moves in the opposite direction to the freight rate.

The effect of these three aspects is determined only by experience and can be time-varying. Thus, the purpose of this study is to explore the dependence structure between oil prices and maritime freight rates to empirically identify the channel.

This study provides three major contributions to the existing relevant literature. First, it investigates and compares the linkage between oil prices and all main sectors of maritime freight rates: the Baltic Dry Index (BDI), the Baltic Dirty Tanker Index (BDTI), and the Baltic Clean Tanker Index (BCTI). Second, this study employs the decomposition method, not studied in the existing literature. There is a lack of research showing systematic relationships by classifying patterns and movements seen in the time series. Thus, our study has a new perspective in analyzing the dependence between crude oil and freight rates of time-series components. Third, we identify the time-varying relationship between different shipping freight markets and crude oil. In analyzing the relationship between multivariate time series, it is necessary to investigate temporal patterns in each univariate series and their joint behavior. Accordingly, we employ the time-varying Student's $t$ and symmetrized Joe-Clayton (SJC) copulas, which have many advantages over other conventional methods. The models capture the conditional dependence and asymmetric tail dependence structures between oil prices and freight rates. The time-varying effects in the dependence can be well identified in the copula modeling. Thus, this method allows us to grasp the time-path behavior more clearly in the maritime freight market. This study contributes to the relevant literature to uncover the asymmetric tail dependence structure between the oil market and maritime transport markets by focusing on the above three aspects.

The main findings of our analysis are as follows: the decomposed components have different conditional dependence patterns, and we discovered asymmetry in the upper and lower tail dependence. In the long-run, more dependence has been found in extreme periods like financial crises. In the short-run fluctuations, we found that the dependence increases in an economic boom.

The implications of the results suggest that dependence can vary over time and may change depending on extreme events. This means that the corresponding strategy of the long- and short-runs should be different. A deep understanding of freight rate behaviors is important to maritime forecasting, portfolio diversification, and risk management in shipping freight markets. As a source of energy fuel to propel ships, oil is one of the major operating expenses of any shipowner. The shipping companies and policymakers in the maritime transport industry should reduce possible uncertainty and risk in shipping freight markets' cost and revenue. Thus, our empirical results can be used as important and necessary information to uncover the linkage between the oil price and shipping freight rates, the main source of uncertainty and risk in the industry. 
The remaining sections of this paper are as follows: a literature review is presented in Section 2. In Section 3, the methodology used in this study is summarized. The preliminary analysis of sample data and empirical findings are presented in Section 4 . Section 5 concludes the analysis.

\section{Literature Review}

Many studies have analyzed the relationship between oil price and freight rates using several methods. Most studies reported evidence of the relationship between oil and maritime freight markets. Among others, Kavussanos [6] discovered that tanker spot prices are negatively connected to the oil price and positively connected to their volatility, by employing the general autoregressive conditional heteroscedasticity (GARCH) model. Glen and Martin [7] explained that an ambiguous connection between freight rates and oil prices could be possible. They insisted that oil price change could be driven by supply and demand variations, which influence the freight rates in opposite directions. Notteboom and Vernimmen [8] analyzed how shipping lines have adapted their service schedules to cope with increased bunker costs using a cost model. They found that shipping lines respond to higher bunker costs late. Poulakidas and Joutz [9] showed that tanker demand comes from the oil demand, and thus tanker rates respond highly to the oil prices. El-Masry et al. [10] explored the influence of macroeconomic factors, including oil prices, on shipping firms' stock returns. They found that an increase in oil prices significantly influences the minority of shipping companies. UNCTAD (United Nations Conference on Trade and Development) [11] investigated the impact of oil prices on maritime freight rates for containerized goods and found that the elasticity of container freight rates to oil prices has increased since 2004. Shi et al. [12] examined the linkage between fluctuations in the freight rates and oil prices, employing a structural vector autoregressive model. They found that oil supply shocks have a significant influence on the maritime freight market. Yang et al. [13] analyzed the spillover effects of the oil market on the tanker market using a VAR-BEKK-GARCH model. They found that oil market volatility has a significant influence on the tanker market. Gavriilidis et al. [14] discovered that considering oil demand shocks significantly improves the forecasting accuracy of tanker freight rate volatility, while considering oil supply shocks has a very limited influence on the volatility forecasting results. Maitra et al. [15] investigated the volatility transmission between oil and liner shipping stock returns using dynamic conditional equicorrelations and the directional spillover index approach. They found that the linkage between stock returns of crude oil and liner shipping companies became more volatile. Siddiqui and Basu [16] explored the cross-correlation between pairs of oil and freight price cycles to uncover the non-linear linkage between them by employing the decomposition method. They found ever-enhancing relations in the medium to longer terms, which are mostly induced by oil prices.

Michail and Melas [17] found that the BDI had no statistically significant relationship, but the BDTI and the BCTI had a negative relationship with Brent oil. Angelopoulos et al. [18] discovered that oil prices are widely linked to the shipping market because of the fact that there is a lead-lag relationship with freight rates.

Contrary to the above studies, Alizadeh and Nomikos [19] examined the dynamic linkage between crude oil prices and tanker freight rates across two major tanker routes. They found no evidence supporting the tanker freight rates and spot and futures price differentials in the oil market.

Some studies employed the copula approach to analyze maritime freight rates. Among others, Zhang [20] developed copula-based models for analyzing oil price and tanker freight rates and revealed weak dependence between the two variables at the time of high oil prices. Li et al. [21] examined the connectedness among different shipping freight rates by using GARCH-copula models and found non-linear dynamic linkages among freight rate returns. Bai and Lam [22] investigated dynamic interdependence between the liquefied petroleum gas (LPG) freight rate and oil price employing a conditional copula-GARCH approach and found that the price linkage between crude oil and the Baltic LPG freight rate is relatively weak and mostly positive. Sun et al. [23] addressed the extreme risk transmission from the commodity market to the maritime market by employing a 
GARCH-copula-CoVaR approach. They found evidence regarding risk spillovers from the oil to maritime markets.

Few studies analyzed asymmetric tail dependence. Reboredo and Ugolini [24] examined downside and upside price spillovers between precious metals by employing a vine-copula model and measuring downside and upside value-at-risk and conditional value-at-risk. They revealed that the interdependency is different across precious metals, showing different average and tail dependence features. Jondeau [25] explored the tail dependence between the US equity portfolios and discovered asymmetry in the lower and upper tail dependence.

However, these two studies only analyzed the asymmetric tail dependence of precious metals and equities and did not focus on the interdependence between oil price and freight rates. Thus, our study is the first to analyze the asymmetric tail dependence between oil price and maritime freight rates.

\section{Methodology}

A copula function decouples the multivariate distribution function from its marginal distribution function. A copula method is useful for modelling correlated random variables. Traditional dependence measures pairwise dependence, but a copula measures the dependence structure among all random variables. This method can construct a more flexible multivariate distribution without the limitations of the marginal distribution selection and describes how marginals are combined in the joint distribution. Thus, we can model the dependence structure and marginal separately. The copula approach is applied to model the dependence and tail dependence of the monthly crude oil price and freight rates.

A copula function is divided into marginal and joint distributions. This paper uses the original index value to transform marginal distribution first. Then copula approaches are employed to explore the time-varying dependence between oil and freight rates.

We used the time-varying Student's $t$ and SJC copulas, proposed by Patton [26]. The time-varying Student's $t$ copula was used to capture dependence. The time-varying SJC copula was employed to capture the tail dependence. It is commonly used because it allows for symmetrical or asymmetrical dependence on the tail. First, the time-varying Student's $t$ copula is briefly discussed below.

$$
\rho_{t}=\Lambda\left(\omega_{\rho}+\beta_{\rho} \rho_{t-1}+\alpha_{\rho} \frac{1}{q} \sum_{i=1}^{q} T^{-1}\left(u_{t-i} ; v\right) T^{-1}\left(v_{t-i} ; v\right)\right)
$$

Here $\Lambda(\cdot) \equiv \frac{\left(1-e^{-x}\right)}{\left(1+e^{-x}\right)}$, a transformation function, holds the parameter $\rho_{t}$ within $(-1,1)$ interval. $T^{-1}(\cdot)$ is the inverse of Student's $t$ CDF (cumulative density function). $\rho_{t}$ is the conditional dependence. $\rho_{t-1}$ is the previous conditional level and represents the persistence effect. $\alpha_{\rho}$ captures the variability of dependence. This model assumes the functional form by following the ARMA $(1, q)$ process.

Additionally, to estimate the upper-lower tail dependence, we use the SJC copula [26]. We assume that the time-varying SJC copula follows the ARMA $(1, q)$ process. Thus, the time-varying SJC copula that follows this process is as given below:

$$
\begin{aligned}
& \tau_{t}^{U}=\Lambda\left(\omega_{U}+\beta_{U} \tau_{t-1}^{U}+\alpha_{U} \cdot \frac{1}{q} \sum_{i=1}^{q}\left|u_{t-i}-v_{t-i}\right|\right) \\
& \tau_{t}^{L}=\Lambda\left(\omega_{L}+\beta_{L} \tau_{t-1}^{L}+\alpha_{L} \cdot \frac{1}{q} \sum_{i=1}^{q}\left|u_{t-i}-v_{t-i}\right|\right)
\end{aligned}
$$

where $\tau^{U}$ is the upper tail and $\tau^{L}$ indicates the lower tail dependence. $\Lambda(\cdot) \equiv\left(1+e^{-x}\right)^{-1}$ is the logistic transformation function, which holds the $\tau^{U}$ and $\tau^{L}$ in the range $(0,1)$. 


\section{Empirical Analysis and Results}

\subsection{Sample Data}

Although the shipping freight rates are low and volatile nowadays, they behave differently in different shipping freight markets. As Clarksons Research [27] explained, there is usually another strong market when one market performs weakly, highlighting the need to study shipping freight rates by shipping freight markets. Thus, we use the data of three sub-freight markets of maritime transport, as published by the Baltic Exchange in London: the Baltic Dry Index (BDI), freight rates for the transport of raw materials such as iron ore, coal, and grain; the Baltic Clean Tanker Index (BCTI), freight rates for the transport of petroleum products such as gasoline and diesel; and the Baltic Dirty Tanker Index (BDTI), freight rates for oil tankers. We used the monthly data of Brent crude oil, BDI, BCTI, and BDTI, during the period January 2007-May 2020, which gives 160 observations for each variable. We collected the data from Informax.

\subsection{Decomposition}

The decomposition of the time series can classify the characteristics of patterns and components seen in the time series. It separates them into "trend", "seasonal", and "remainder" components. The trend component identifies trends in the long-run; it describes the long-run increases or decreases. Seasonal components have a constant cycle and identify patterns that change repeatedly. Finally, the remainder component represents the short-run fluctuation. In this paper, Brent oil prices and freight rates are decomposed using the seasonal and trend decomposition (STL) method by Cleveland et al. [28]. STL is a method that decomposes trend and seasonality using LOESS (locally weighted polynomial regression). The main feature of this method is its resiliency for outliers in the data, which makes it possible to have a robust series of component sub-series. Moreover, STL is not limited to monthly and quarterly data because these do not constrain seasonal patterns to take certain forms. Thus, this method handles any kind of seasonality, including monthly or quarterly data, unlike SEATS and X11.

The STL decomposition procedure is as follows. First, use the LOESS regression to estimate the approximate trend of the data and store it in the trend component. Then, using the inner loop and outer loop algorithms, the data are estimated to be the same at each cycle point and the corresponding values are stored in the seasonal component. The remainder component is then the raw data at each time minus the trend and seasonal values. According to an additive decomposition form, the function is expressed as follows:

$$
Y_{t}=T_{t}+S_{t}+R_{t}
$$

where $T_{t}$ is the trend component, $S_{t}$ is the seasonal component, and $R_{t}$ is the remainder component. It was decomposed by applying the STL package of R software (http://CRAN.R-project.org/package= stlplus). STL method selects parameters in order to determine the smoothing of the trend and seasonality. For some smoothing parameters, the default values specified in the package were applied. However, the smoothing of seasonal data is important. The seasonal smoothing parameter plays a critical role in determining changes in other components. Thus, in this paper, the most commonly used method was applied. The seasonal smoothing parameter was set as "periodic option (constant value)" and the seasonal effect was estimated.

The graphical representation of the time series and decomposed components of Brent, BDI, BCTI, and BDTI is illustrated in Figure 1. In Figure 1, the movement of the Brent oil prices show that prices rose sharply and fell sharply during 2008-2010. The price has fallen after maintaining a high price from 2012-2015. The maritime freight rates had increased at the beginning of the sample period but fell sharply in 2009. These rates had little rise and fall during the 2010-2020, but recently, BCTI and BDTI have increased sharply. 


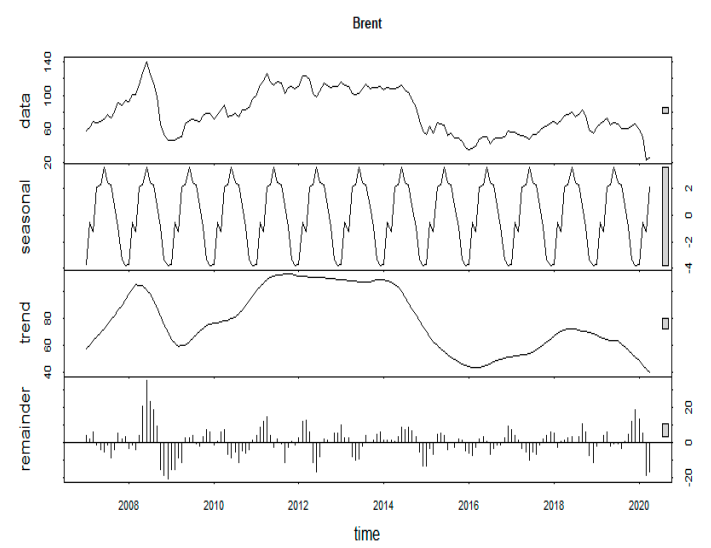

(a) Brent

BCII

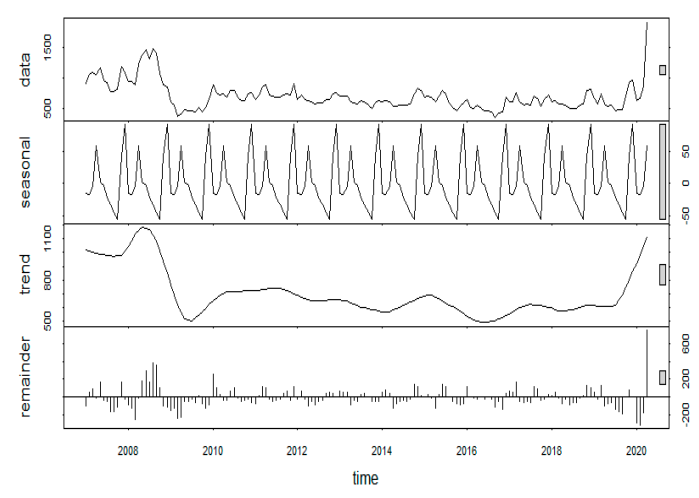

(c) BCTI
BOI

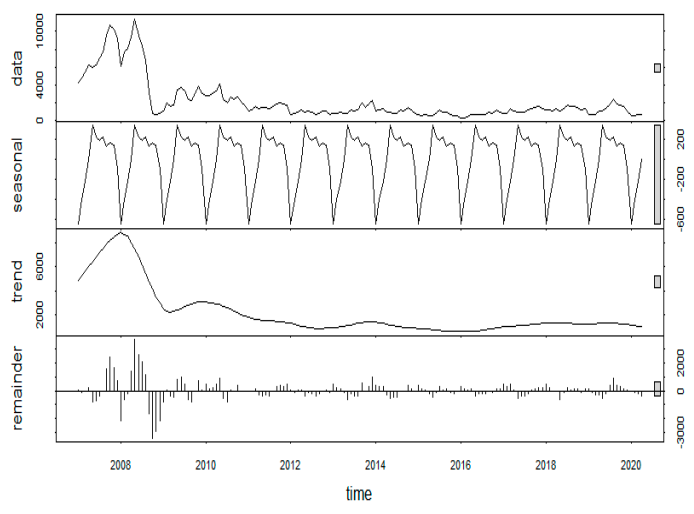

(b) BDI

BDTI

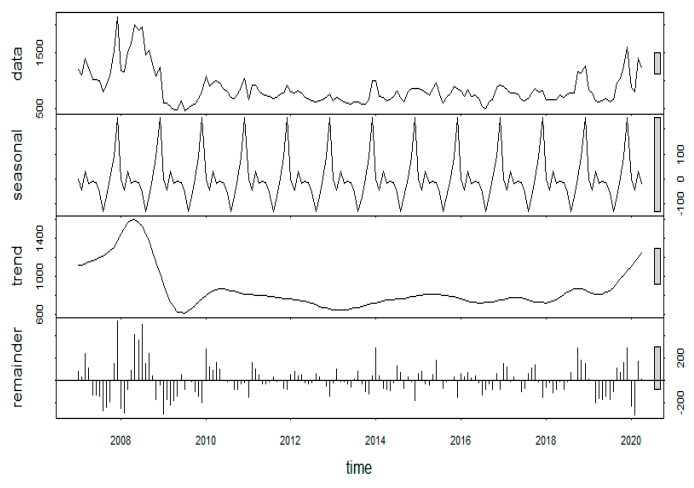

(d) BDTI

Figure 1. Time series plot and decomposed components of Brent, the BDI, the BCTI, and the BDTI.

The maritime freight rates are showing similar movements, but BCTI and BDTI have been rising recently. There are relatively many short-run fluctuations in BDTI, looking at the remainder component.

Comparing the decomposed components, the linkage between crude oil prices and maritime freight rates trend components are dissimilar, while BCTI and BDTI show similar patterns. Additionally, the seasonal and remainder component patterns are different in each variable. Overall, the decomposed component results show that each component in the time series is different, indicating that it is important to analyze the decomposed components' dependency.

\subsection{Time-Varying Dependence Results}

Based on the estimates of copula parameters presented in Table 1, the descriptive statistics of the time-varying dependence are displayed in Table 2. Figures 2-4 depict the evolution of dependence between maritime freight rates and crude oil over time. As in panel A of Table 2, the average time-varying dependence between Brent and the BDTI is negative (-0.1114), and between Brent and the BDI/Brent and the BCTI is positive $(0.1415,0.1050)$. It was found that the dependence between Brent and the BDI was the strongest. From a long-term perspective, the negative dependence between Brent and the BDTI means that a rise in crude oil prices will reduce the volume of transport services, leading to lower freight rates. However, crude oil price and the BDI (and the BCTI) are found to have a positive relationship, which means that rising crude oil prices and demand for crude oil will result in higher fares due to increased costs and increased maritime freight volume. Thus, this implies that the BDI and the BCTI are related to shipping companies' transportation costs and crude oil demand, but the BDTI is related to crude oil transportation services 
Table 1. Results of the time-varying Student's $t$ copula.

\begin{tabular}{|c|c|c|c|c|c|}
\hline \multicolumn{6}{|c|}{ Panel A. Trend } \\
\hline & $\omega_{\rho}$ & $\beta_{\rho}$ & $\alpha_{\rho}$ & $v$ & AIC \\
\hline Brent/BDI & $\begin{array}{c}0.0079 \\
(0.2939)\end{array}$ & $\begin{array}{c}1.5817^{* * *} \\
(0.3354)\end{array}$ & $\begin{array}{l}-0.4983 \\
(0.9188)\end{array}$ & $\begin{array}{c}14.9997^{* *} \\
(7.4949)\end{array}$ & -94.1023 \\
\hline Brent/BCTI & $\begin{array}{c}-1.1610^{* * *} \\
(0.3191)\end{array}$ & $\begin{array}{c}1.2494^{* * *} \\
(0.4060)\end{array}$ & $\begin{array}{l}-0.3961 \\
(1.1687)\end{array}$ & $\begin{array}{l}14.9999^{*} \\
(7.9541)\end{array}$ & -67.4002 \\
\hline Brent/BDTI & $\begin{array}{l}-0.1695 \\
(0.1547)\end{array}$ & $\begin{array}{l}1.1797^{* *} \\
(0.4890)\end{array}$ & $\begin{array}{c}0.6775 \\
(0.8829)\end{array}$ & $\begin{array}{c}14.9997^{* *} \\
(5.9410)\end{array}$ & -63.5371 \\
\hline \multicolumn{6}{|c|}{ Panel B. Seasonal } \\
\hline Brent/BDI & $\begin{array}{c}0.1912 \\
(1.9665)\end{array}$ & $\begin{array}{c}0.1532 * * * \\
(0.0231)\end{array}$ & $\begin{array}{c}0.0997 \\
(3.3384)\end{array}$ & $\begin{array}{c}5.0000 * * * \\
(0.8740)\end{array}$ & -74.0731 \\
\hline Brent/BCTI & $\begin{array}{c}-2.0283^{* * *} \\
(0.3049)\end{array}$ & $\begin{array}{c}-4.4851^{* * *} \\
(0.9144)\end{array}$ & $\begin{array}{c}0.2443 \\
(0.3730) \\
\end{array}$ & $\begin{array}{c}5.0000^{* * *} \\
(1.0342)\end{array}$ & -57.2134 \\
\hline Brent/BDTI & $\begin{array}{c}-3.6848^{* * *} \\
(1.1416)\end{array}$ & $\begin{array}{c}-1.7579 * * \\
(0.7629)\end{array}$ & $\begin{array}{l}-0.9887 \\
(1.1614)\end{array}$ & $\begin{array}{c}5.0000^{* * *} \\
(1.2499)\end{array}$ & -98.3152 \\
\hline \multicolumn{6}{|c|}{ Panel C. Remainder } \\
\hline Brent/BDI & $\begin{array}{l}0.7825 * \\
(0.4664)\end{array}$ & $\begin{array}{l}0.4083^{* *} \\
(0.1985)\end{array}$ & $\begin{array}{c}-1.6808^{* *} \\
(0.6709)\end{array}$ & $\begin{array}{l}5.0121 * \\
(2.6340)\end{array}$ & -40.5075 \\
\hline Brent/BCTI & $\begin{array}{c}0.3331 \\
(0.4205) \\
\end{array}$ & $\begin{array}{l}0.4560 * \\
(0.2549)\end{array}$ & $\begin{array}{c}-1.9655^{* * *} \\
(0.2342)\end{array}$ & $\begin{array}{c}3.6300 * * * \\
(1.4069)\end{array}$ & -33.6880 \\
\hline Brent/BDTI & $\begin{array}{l}0.7411 \text { * } \\
(0.4145)\end{array}$ & $\begin{array}{c}0.2796 \\
(0.2135)\end{array}$ & $\begin{array}{c}-1.6777^{* *} \\
(0.8316)\end{array}$ & $\begin{array}{c}3.2386^{* * *} \\
(1.2523)\end{array}$ & -35.0155 \\
\hline
\end{tabular}

Notes: Standard errors are in parentheses for all parameters. The AIC is the value of Akaike information criterion for each pair. For modeling time-varying copula, the lag order $q$ in Equation (1) was set to 10 following Patton [26]. $* * * * *$ and $*$ indicate the $1 \%, 5 \%$, and $10 \%$ levels of significance, respectively.

Table 2. Descriptive statistics of the dynamic dependence.

\begin{tabular}{cccccc}
\hline \multicolumn{5}{c}{ Panel A. Trend } \\
\hline & Mean & Median & Maximum & Minimum & Std. Dev. \\
\hline Brent/BDI & 0.1415 & 0.0760 & 0.9911 & -0.6916 & 0.4017 \\
\hline Brent/BCTI & 0.1050 & 0.0231 & 0.9560 & -0.7204 & 0.3564 \\
\hline Brent/BDTI & -0.1114 & -0.1090 & 0.7205 & -0.8921 & 0.4449 \\
\hline \multicolumn{5}{c}{ Panel B. Seasonal } \\
\hline Brent/BDI & 0.6388 & 0.6370 & 0.8253 & 0.6125 & 0.0214 \\
\hline Brent/BCTI & -0.0992 & 0.0342 & 0.5424 & -0.9430 & 0.4055 \\
\hline Brent/BDTI & -0.6326 & -0.6128 & -0.3550 & -0.8711 & 0.1015 \\
\hline & \multicolumn{5}{c}{ Panel C. Remainder } \\
\hline Brent/BDI & 0.2665 & 0.2328 & 0.7847 & 0.0943 & 0.1312 \\
\hline Brent/BCTI & 0.1346 & 0.0950 & 0.7042 & -0.1955 & 0.1540 \\
\hline Brent/BDTI & 0.2482 & 0.2178 & 0.6711 & 0.1026 & 0.1036 \\
\hline & \multicolumn{5}{c}{}
\end{tabular}

The dynamic dependence between Brent and the BDTI is the largest standard deviation (0.4449), while the dynamic dependence between Brent and the BCTI is the lowest standard deviation (0.3564). Overall, all pairs were found to be highly volatile.

As panel B of Table 2 indicates, the average dependence between Brent and the BCTI/Brent and the BDTI is negative $(-0.0992,-0.6326)$, respectively, and between Brent and the BDI is positive $(0.6388)$. We found that Brent and the BDI has the strongest dependence, and the BDTI and the BDI present opposite results. The volatility for the dynamic dependence between Brent and the BCTI is the largest standard deviation (0.4055), while the dynamic dependence between Brent and the BDI is the lowest 
standard deviation (0.0214). For the seasonal component, the same explanation as the conclusion of the trend component holds.

Finally, as shown in panel $\mathrm{C}$ of Table 2, unlike other components, the average dependence of all pairs is positive. The dependence between Brent and the BDI is the highest. However, lesser volatility was found compared to other components. From the short-run fluctuation, the rise in crude oil prices leads to an immediate rise in costs, which leads to higher freight rates. Figures $2-4$, based on Equations (2) and (3) and the parameter estimates shown in Table 1, plot the time path of the dependence between oil and freight rates during the sample period. The dependence between oil and freight rates differs the patterns and behavior in the decomposed components. Figure 2 reports the time-varying dependence of the trend component. In the middle of 2008, Brent and freight rates show a strong positive. Then the dependence for all pairs is negative during 2010-2011 and 2013-2014, having the highest dependence in 2016 due to the impact of Brexit, weak growth, and choppy markets. The time-varying dependence for seasonal components between Brent and freight rates is shown in Figure 3. The dependence between Brent and the BCTI shows that the variation is higher than in other pairs. Finally, as in Figure 4, the remainder components move similarly in all pairs. The highest dependence is seen between 2009 and 2010, which implies that the relationship between variables increased during the US financial crisis. Overall, when an extreme event happens, a strong dependence is shown. Compared to the decomposed components' results for the trend component, while dependence reacts sensitively to extreme events, the seasonal component does not.

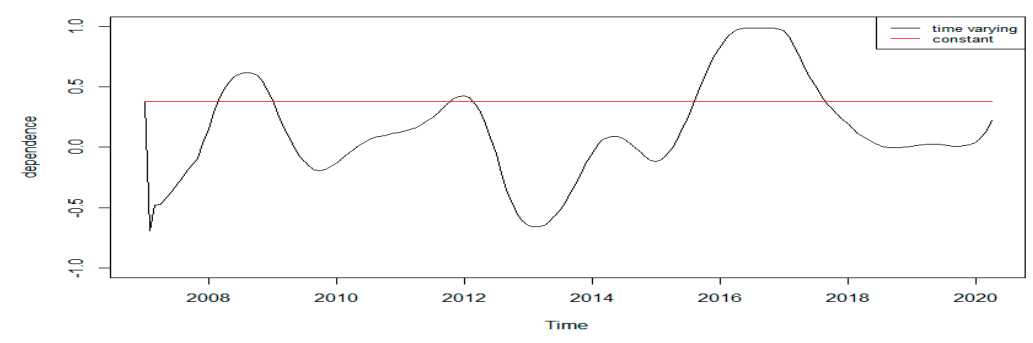

(a) Brent/BDI

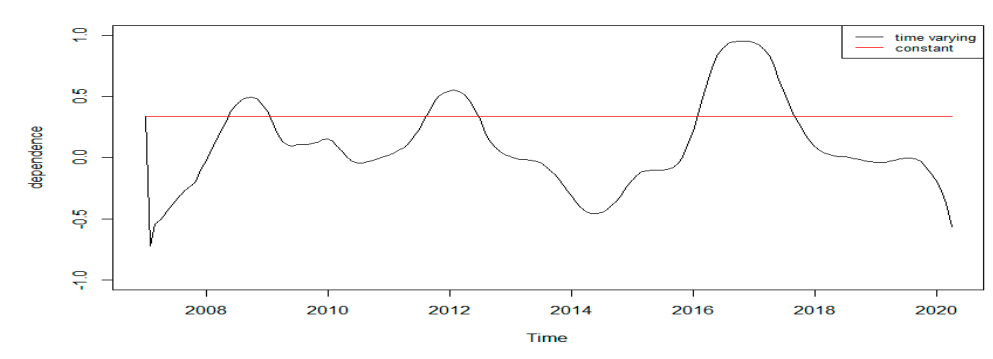

(b) Brent/BCTI

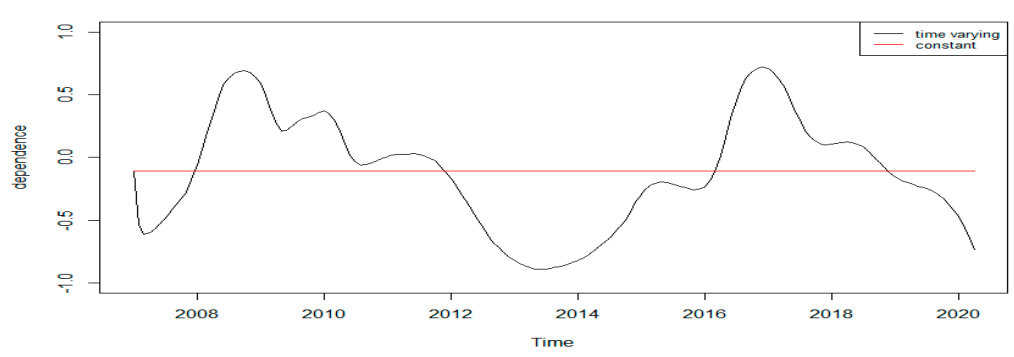

(c) Brent/BDTI

Figure 2. Dependence of the trend component for pairs. 


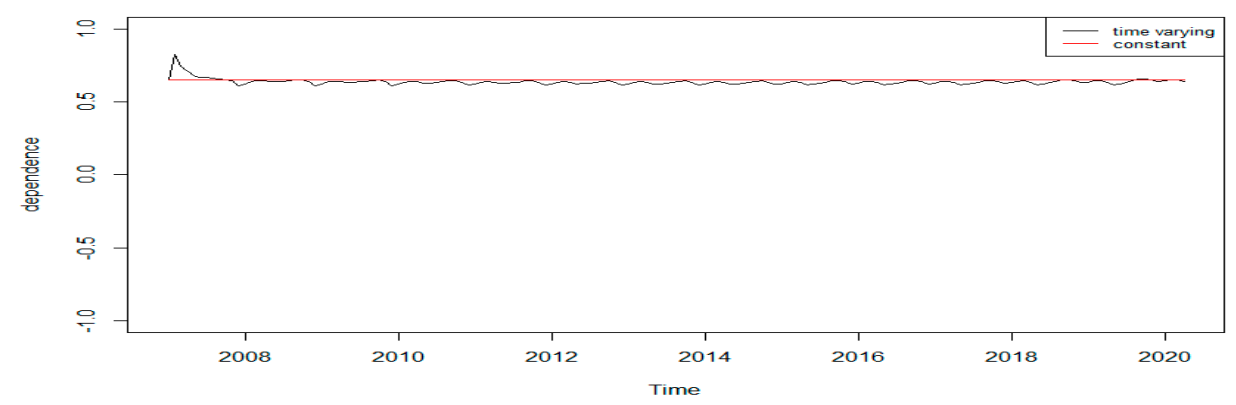

(a) Brent/BDI

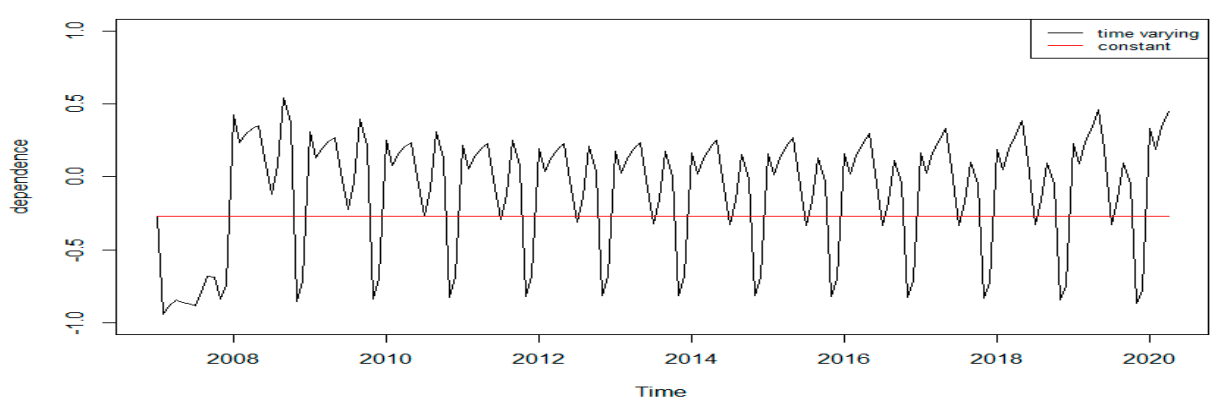

(b) Brent/BCTI

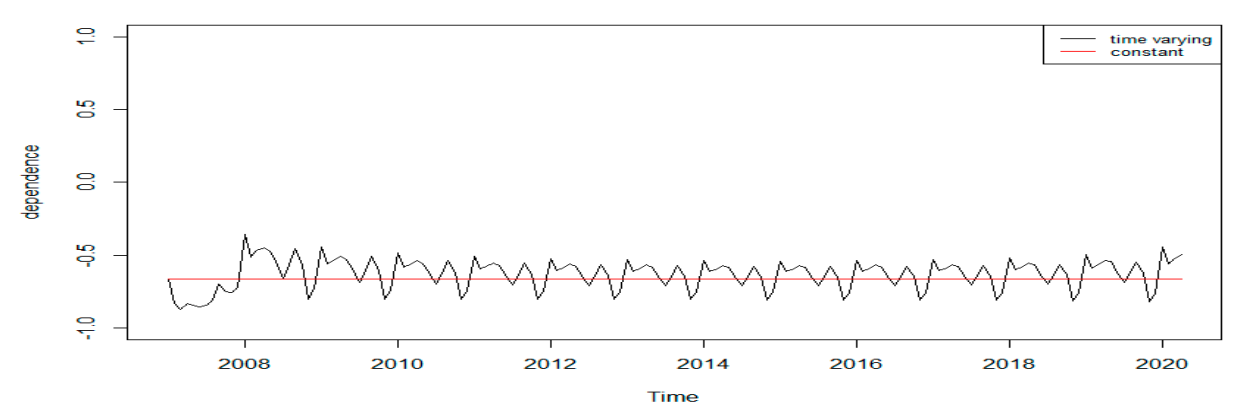

(c) Brent/BDTI

Figure 3. Dependence of the seasonal component for pairs.

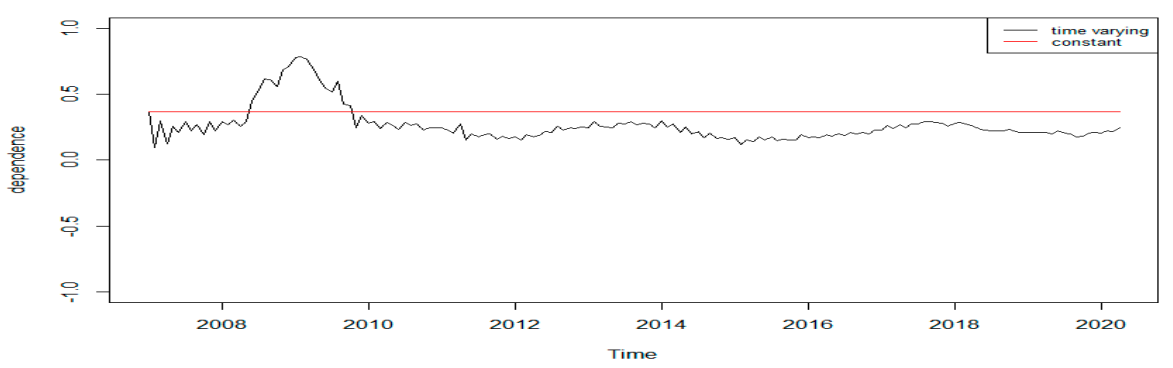

(a) Brent/BDI

Figure 4. Cont. 


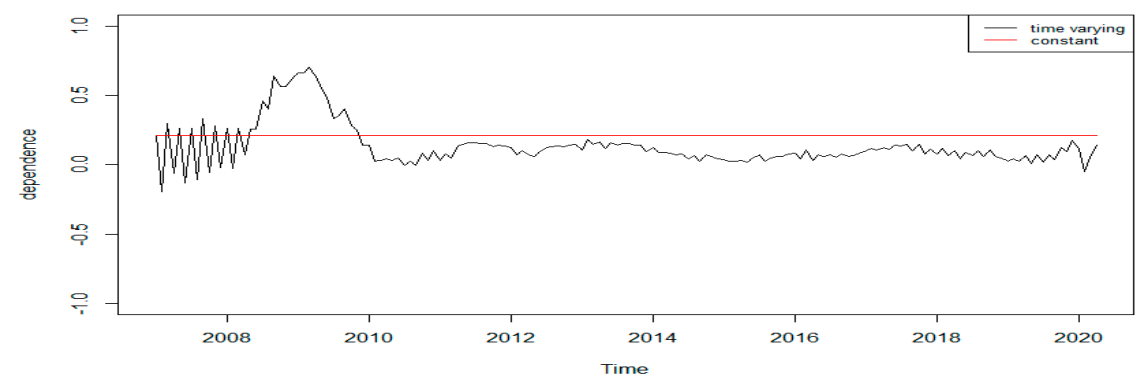

(b) Brent/BCTI

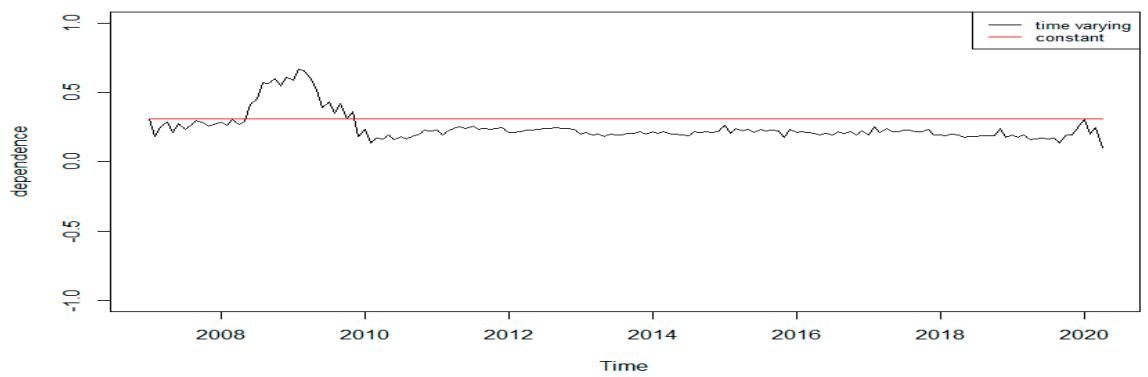

(c) Brent/BDTI

Figure 4. Dependence of the remainder component for pairs.

\subsection{Time-Varying Tail Dependence Results}

Tail dependencies are very useful for analyzing the influence of extreme events. Lower tail dependence means co-movements increase more in extreme events, such as a financial crisis or Brexit. However, the upper tail dependence means co-movements increase more in economic boom periods. Based on the copula parameters presented in Table 3, the descriptive statistics of the time-varying tail dependencies are shown in Tables 4-6. Figures 5-7 depict the time path of tail dependence between freight rates and crude oil, which present time-varying characteristics over time. Table 4 shows the descriptive statistics for the tail dependence of the trend component. The freight rates had a positive lower tail dependence with crude oil. However, the upper tail dependence was close to zero during the sample period. We found that there is an asymmetric tail dependence. We found that the pair between Brent and the BDI has the strongest dependence (0.4602), with the pair of Brent and the BCTI being the lowest in mean level (0.2432). In terms of volatility, lower tail dependence between Brent and the BDI had the largest standard deviation. Overall, our findings have shown a lower tail dependence in all pairs of trend components. If crude oil prices fall, freight rates fall. These results show the existence of an asymmetric tail dependence between oil and freight rates, which indicates a higher dependence on a recession and crash than on an expansion and boom.

Table 3. Results of the time-varying SJC copula.

\begin{tabular}{cccc}
\hline \multicolumn{5}{c}{ Panel A. Trend } \\
\hline$\omega_{U}$ & $-10.4073(2.4523)^{* * *}$ & $-9.9001(2.8714)^{* * *}$ & $-4.9053(1.8031)^{* * *}$ \\
\hline$\beta_{U}$ & $-0.5923(2.1069)$ & $-9.4402(5.3444)^{*}$ & $-9.9836(2.1519)^{* * *}$ \\
\hline$\alpha_{U}$ & $0.0045(1.0001)$ & $0.1998(0.9679)$ & $-1.4274(0.0571)^{* * *}$ \\
\hline$\omega_{L}$ & $5.3496(0.0829)^{* * *}$ & $3.2528(0.7102)^{* * *}$ & $1.2914(0.0393)^{* * *}$ \\
\hline$\beta_{L}$ & $-14.3559(3.6421)^{* * *}$ & $-9.9999(5.3147)^{*}$ & $-9.9999(0.0754)^{* * *}$ \\
\hline$\alpha_{L}$ & $-3.8566(0.4930)^{* * *}$ & $-2.3200(0.7949)^{* * *}$ & $1.1606(0.0453)^{* * *}$ \\
\hline AIC & -114.9619 & -76.7813 & -17.8445 \\
\hline
\end{tabular}


Table 3. Cont.

\begin{tabular}{cccc}
\hline \multicolumn{4}{c}{ Panel B. Seasonal } \\
\hline$\omega_{U}$ & $-2.8822(6.0745)$ & $-15.4850(228.2767)$ & $-15.9229(44.1790)$ \\
\hline$\beta_{U}$ & $4.9929(30.2431)$ & $-1.9252(67.1816)$ & $-0.0126(1.1915)$ \\
\hline$\alpha_{U}$ & $3.7201(1.8230)^{* *}$ & $0.0063(1.1358)$ & $0.0350(2.0439)$ \\
\hline$\omega_{L}$ & $-2.9914(5.2964)$ & $-14.3271(60.4751)$ & $-15.2534(65.6691)$ \\
\hline$\beta_{L}$ & $4.9950(27.8251)$ & $-1.0149(20.7762)$ & $-0.7769(39.5632)$ \\
\hline$\alpha_{L}$ & $4.0796(0.2375)^{* * *}$ & $0.0093(1.0463)$ & $0.0305(1.8479)$ \\
\hline $\mathrm{AIC}$ & -76.8316 & -5.5420 & 2.3875 \\
\hline \multicolumn{4}{c}{ Panel C. Remainder } \\
\hline$\omega_{U}$ & $-0.8485(1.1235)$ & $-0.3306(5.3986)$ & $1.2178(1.4987)$ \\
\hline$\beta_{U}$ & $-4.9999(4.1836)$ & $-4.9997(8.7713)$ & $-4.9985(6.0124)$ \\
\hline$\alpha_{U}$ & $3.2467(1.3242)^{* *}$ & $0.7359(16.8868)$ & $-1.6328(2.8994)$ \\
\hline$\omega_{L}$ & $-0.6895(0.7630)$ & $-1.4432(3.6187)$ & $-4.9984(4.7115)$ \\
\hline$\beta_{L}$ & $-5.0000(3.0861)$ & $-4.9997(12.5020)$ & $-4.9975(7.4477)$ \\
\hline$\alpha_{L}$ & $2.8619(0.8451)^{* * *}$ & $4.6257(5.6482)$ & $-0.1557(1.0587)$ \\
\hline
\end{tabular}

Notes: Standard errors are in parentheses for all parameters. The AIC is the value of Akaike information criterion for each pair. For modeling time-varying copula, the lag order $q$ in Equations (2) and (3) was set to 10 following Patton [26]. ${ }^{* * *}, * *$, and ${ }^{*}$ indicate the $1 \%, 5 \%$, and $10 \%$ levels of significance, respectively.

Table 4. Descriptive statistics of the dynamic tail dependence of the trend component.

\begin{tabular}{cccccc}
\hline \multicolumn{5}{c}{ Panel A. Lower Tail Dependence } \\
\hline Mrent/BDI & 0.4602 & 0.4637 & 0.8630 & 0.0033 & 0.2699 \\
\hline Brent/BCTI & 0.4467 & 0.4624 & 0.7594 & 0.0091 & 0.2087 \\
\hline Brent/BDTI & 0.2432 & 0.1908 & 0.7476 & 0.0000 & 0.2281 \\
\hline \multicolumn{5}{c}{ Panel B. Upper Tail Dependence } \\
\hline Brent/BDI & 0.0010 & 0.0010 & 0.0010 & 0.0000 & 0.0000 \\
\hline Brent/BCTI & 0.0010 & 0.0010 & 0.0010 & 0.0000 & 0.0000 \\
\hline Brent/BDTI & 0.0015 & 0.0013 & 0.0035 & 0.0000 & 0.0000 \\
\hline
\end{tabular}

Table 5. Descriptive statistics of the dynamic tail dependence of the seasonal component.

\begin{tabular}{cccccc}
\hline \multicolumn{5}{c}{ Panel A. Lower Tail Dependence } \\
\hline Mean & Median & Maximum & Minimum & Std. Dev. \\
\hline Brent/BDI & 0.4469 & 0.4489 & 0.6258 & 0.2372 & 0.0882 \\
\hline Brent/BCTI & 0.0009 & 0.0010 & 0.0010 & 0.0000 & 0.0000 \\
\hline Brent/BDTI & 0.0009 & 0.0010 & 0.0010 & 0.0000 & 0.0000 \\
\hline \multicolumn{7}{c}{ Panel B. Upper Tail Dependence } \\
\hline Brent/BDI & 0.3437 & 0.3388 & 0.3940 & 0.2626 & 0.0256 \\
\hline Brent/BCTI & 0.0009 & 0.0010 & 0.0010 & 0.0000 & 0.0000 \\
\hline Brent/BDTI & 0.0000 & 0.0010 & 0.0010 & 0.0000 & 0.0000 \\
\hline
\end{tabular}


Table 6. Descriptive statistics of the dynamic tail dependence of the remainder component.

\begin{tabular}{cccccc}
\hline \multicolumn{5}{c}{ Panel A. Lower Tail Dependence } \\
\hline Brent/BDI & 0.2390 & 0.1937 & 0.5897 & 0.0448 & 0.1511 \\
\hline Brent/BCTI & 0.1033 & 0.0882 & 0.3122 & 0.0182 & 0.0701 \\
\hline Brent/BDTI & 0.0030 & 0.0028 & 0.0060 & 0.0000 & 0.0008 \\
\hline \multicolumn{5}{c}{ Panel B. Upper Tail Dependence } \\
\hline Brent/BDI & 0.2283 & 0.1708 & 0.6501 & 0.0385 & 0.1643 \\
\hline Brent/BCTI & 0.1827 & 0.1878 & 0.3487 & 0.0533 & 0.0710 \\
\hline Brent/BDTI & 0.3540 & 0.3523 & 0.5402 & 0.2106 & 0.0677 \\
\hline
\end{tabular}

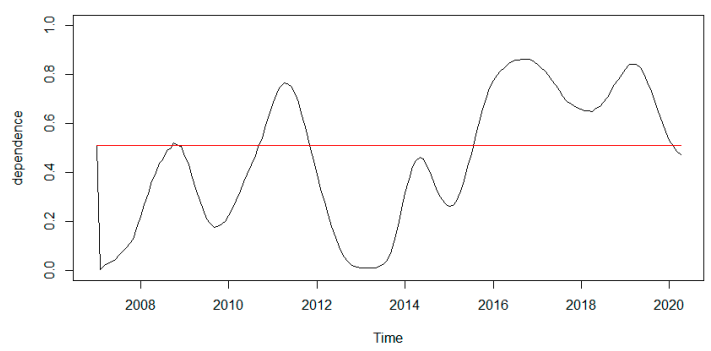

(a) Brent/BDI of lower tail dependence

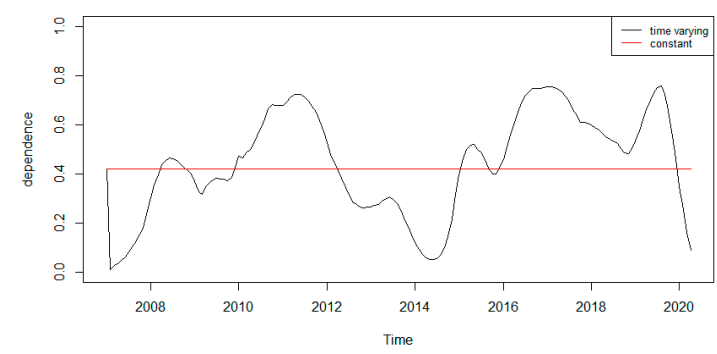

(c) Brent/BCTI of lower tail dependence

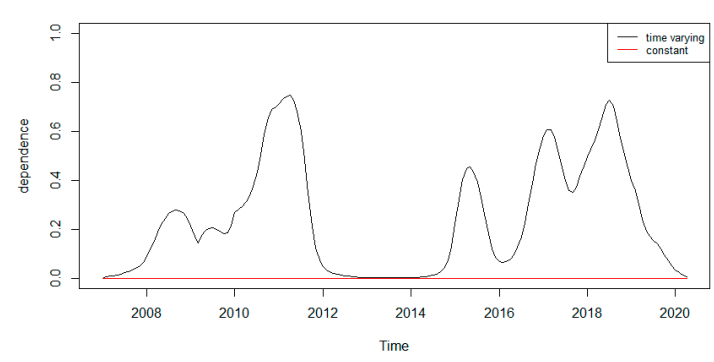

(e) Brent/BDTI of lower tail dependence

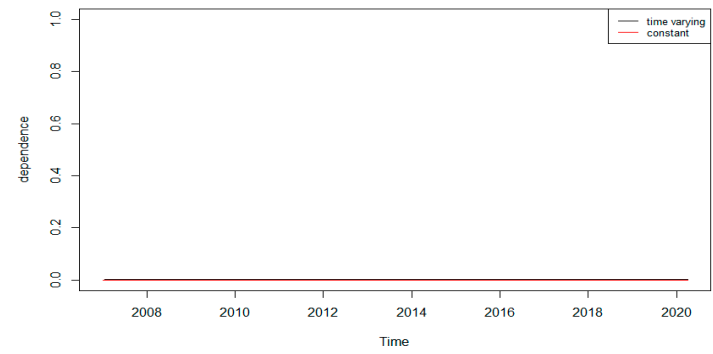

(b) Brent/BDI of upper tail dependence

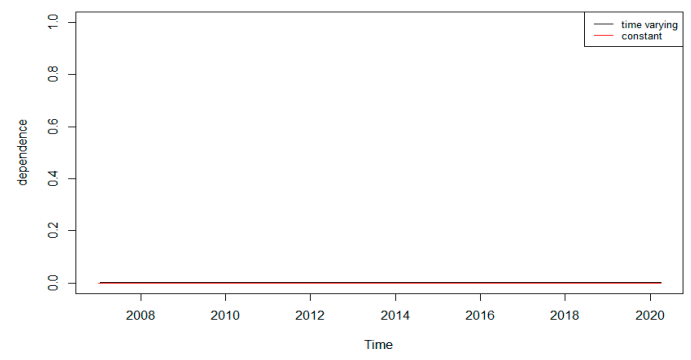

(d) Brent/BCTI of upper tail dependence

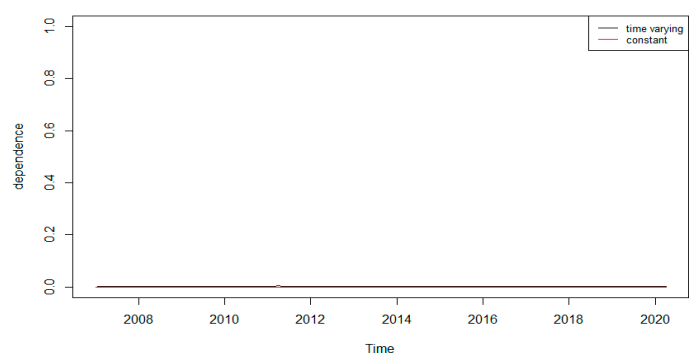

(f) Brent/BDTI of upper tail dependence

Figure 5. Lower and upper tail dependency of the trend component for pairs. 


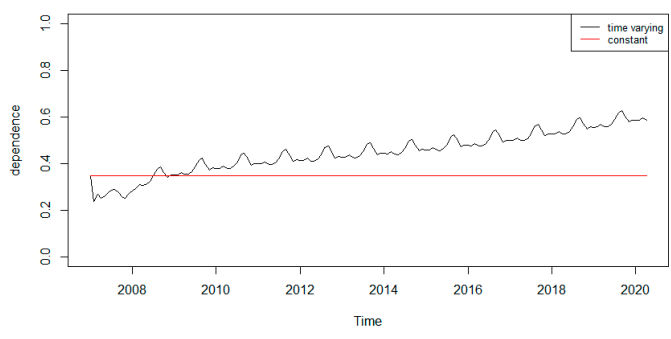

(a) Brent/BDI of lower tail dependence

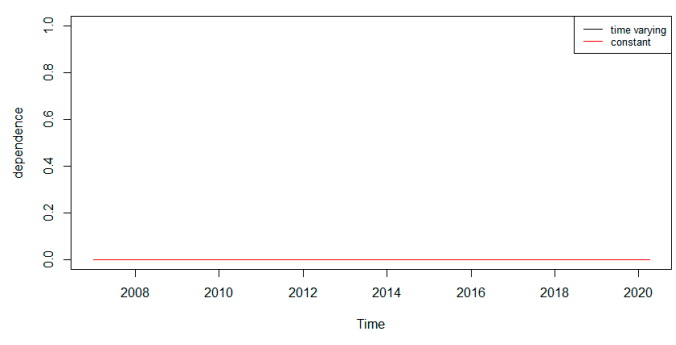

(c) Brent/BCTI of lower tail dependence

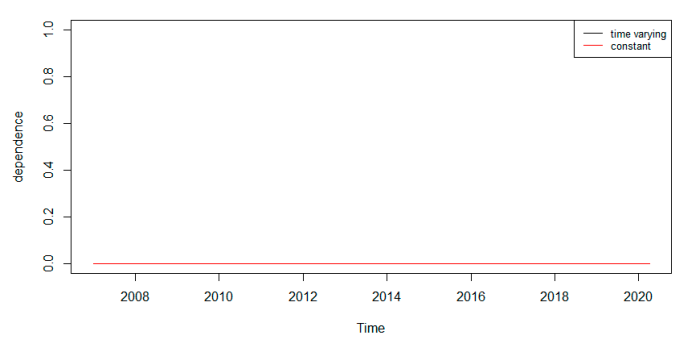

(e) Brent/BDTI of lower tail dependence

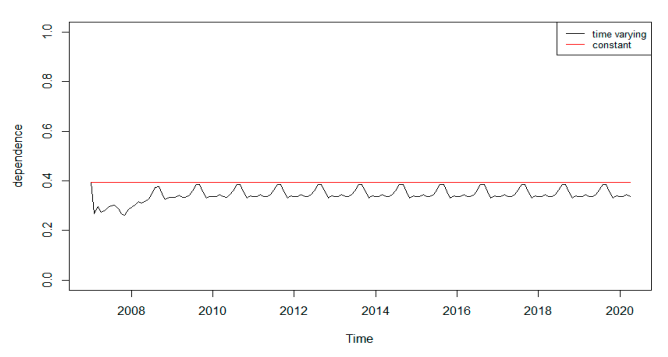

(b) Brent/BDI of upper tail dependence

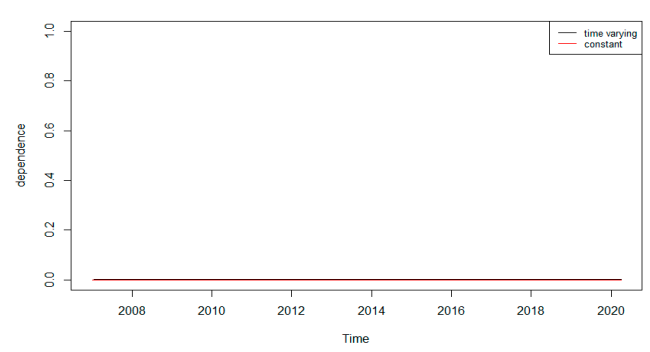

(d) Brent/BCTI of upper tail dependence

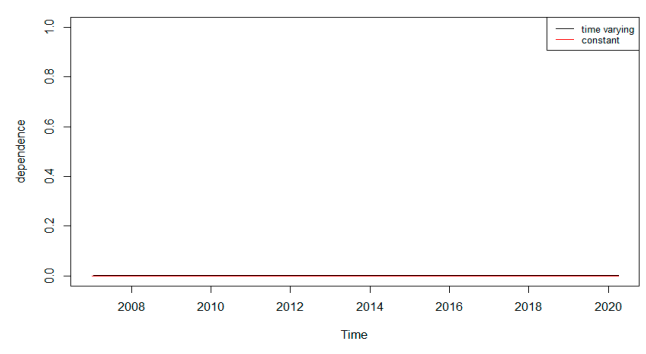

(f) Brent/BDTI of upper tail dependence

Figure 6. Lower and upper tail dependency of the seasonal component for pairs

Table 5 shows a tail dependence between Brent and the BDI, while other pairs had no tail dependence. The results also show higher dependence on the lower tail dependence between Brent and the BDI. In the tail dependence between Brent and the BDI, these results show an asymmetrical tail dependence, implying that co-movements increase more in extreme events.

Table 6 shows the results of tail dependence on the remainder component. The lower tail dependence between Brent and the BCTI was found to be the highest at the mean level. The upper tail dependence showed that the pair of Brent and the BDTI was the highest at the mean level. These results show that asymmetrical tail dependence exists. The pairs of Brent and the BDI/Brent and the BDTI had higher upper tail dependence, meaning that when there is a good extreme event or boom, it becomes more dependent. However, Brent and the BCTI have the opposite result, which means that dependence is higher when a bad extreme event or recession happens. The descriptive statistics of tail dependence show extreme events could spread risk transmission between crude oil and shipping freight rates.

Figures 5-7 present the time path for the lower and upper tail dependence between decomposed crude oil and freight rates. As in Figure 5, during extreme events (the US financial crisis, European debt crisis, and trade war), the lower tail dependence between the trend component of crude oil and freight rates is high. However, this phenomenon is not persistent. 


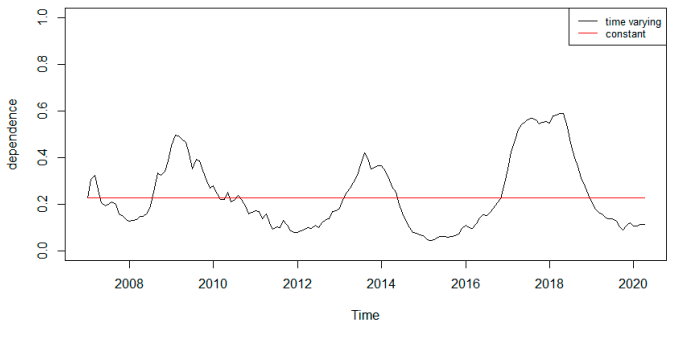

(a) Brent/BDI of lower tail dependence

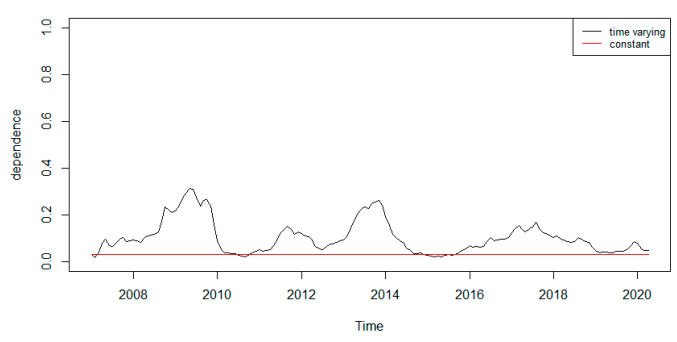

(c) Brent/BCTI of lower tail dependence

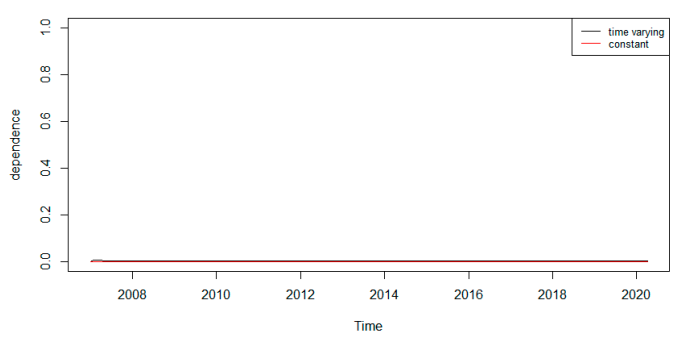

(e) Brent/BDTI of lower tail dependence

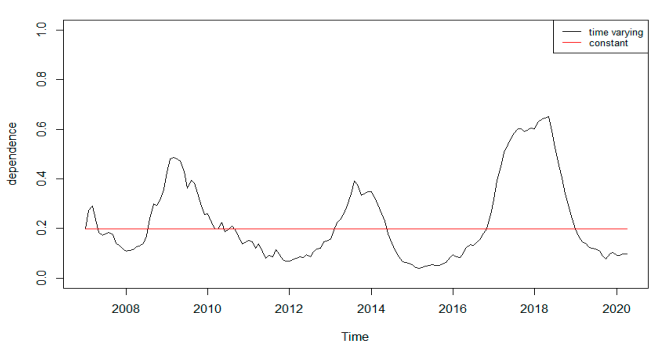

(b) Brent/BDI of upper tail dependence

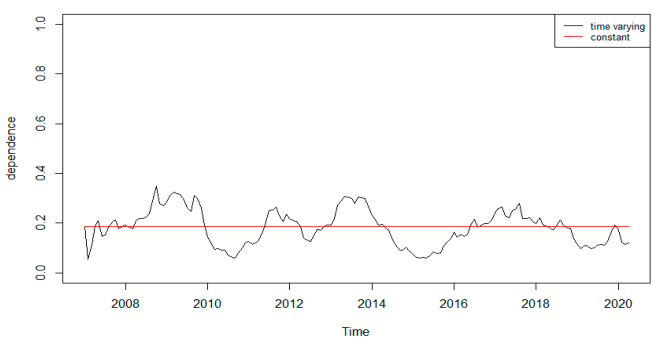

(d) Brent/BCTI of upper tail dependence

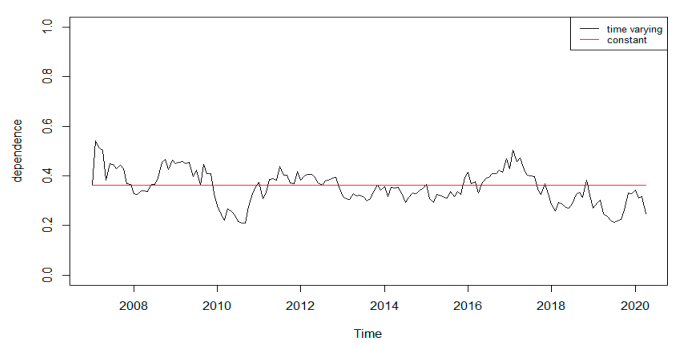

(f) Brent/BDTI of upper tail dependence

Figure 7. Lower and upper tail dependency of the remainder component for pairs.

The Figure 6 plot in time paths between the tail dependencies' seasonal component showed that only a pair of Brent and the BDI existed. The upper tail dependence increases during the sample period; however, dependence is almost stable over time, regardless of extreme events. When compared to the trend component, it suggests that each seasonality component is of little relevance. Thus, these tail dependence results are not important for the analyzed variables. The tail dependence of the remainder component reflects more market movements resulting from short-term fluctuations. As in Figure 7 , comparing the trend and seasonal component, the upper tail dependence of the remainder component is stronger than the lower tail dependence. This is a new finding and an opposite result. That is, when a boom or good event happens, tail dependence increases, and when crude oil prices increase, freight rates go up. Generally speaking, it has been shown that decomposed components have an asymmetric tail dependence. The trend component is highly dependent on extreme events such as the financial crisis, and the remainder component has a strong dependence on economic boom.

\section{Conclusions}

This study investigates the dynamics of asymmetric tail dependence and the downside and upside risk spillovers between oil prices and maritime freight rates along with three sub-freight markets (BDI, BCTI, and BDTI). We draw empirical results using the decomposition method and estimate symmetric and asymmetric time-varying bivariate copula models. 
The empirical findings indicate that time-varying copula methods can explain the dependence structure between crude oil and freight rates. The main findings are as follows: according to the dependence results, the decomposed components have different conditional dependence patterns. The pair of trend and remainder components have a stronger dependence on extreme events than other components. The trend component is more dependent in extreme periods like the financial crisis. That is, in the long-run and short-run, a fall in oil prices is likely to lead to a fall in freight rates. However, we found that dependence of the pair of seasonal components is meaningless.

As a result of tail dependence, we discovered the presence of asymmetric tail dependence of the trend and seasonal components. Thus, we conclude that dependence increased in the recession and increased in an economic boom for the remainder component. In other words, the long-run and short-run fluctuations have the effect of decreasing prices and raising prices, respectively. However, the tail dependence of the seasonal components is found to be nonexistent. In conclusion, the relationship between crude oil and freight rates changes in dependence over time. The relationship is especially important in both the short- and long-run.

The implications of the results suggest that dependence can vary over time and may change depending on extreme events. This suggests that the corresponding strategy for the long-run and short-run should be different. Maritime transport companies and policymakers should consider large fluctuations in the international oil price when determining their freight pricing and maritime transportation decisions. In addition, the current economic environment is changing as consumption of oil and other liquid energy resources decreases and clean energy is developed $[29,30]$. Therefore, in future studies, clean energy should also be considered.

Author Contributions: All the authors contributed to the entire process of writing this paper. K.-H.C. and S.-M.Y. conceived the idea and designed the structure of this paper, K.-H.C. collected and examined the data and devised the methodology, K.-H.C. wrote the draft of Sections 1-3, S.-M.Y. wrote Sections 4 and 5, and S.-M.Y. performed a final revision of the entire paper. All authors have read and agreed to the published version of the manuscript.

Funding: This work was supported by the Ministry of Education of the Republic of Korea and the National Research Foundation of Korea (NRF-2020S1A5B8103268).

Acknowledgments: The authors give thanks to the anonymous reviewers and all the editors in the process of manuscript revision.

Conflicts of Interest: The authors declare no conflict of interest.

\section{References}

1. UNCTAD. Review of Maritime Transport 2017; United Nations: New York, NY, USA, 2017.

2. Kutin, N.; Moussa, Z.; Vallée, T. Factors Behind the Freight Rates in the Liner Shipping Industry. Working Papers Halshs-01828633, HAL. 2018. Available online: https://halshs.archives-ouvertes.fr/halshs-01828633 (accessed on 8 August 2020).

3. UNCTAD. Maritime Transport; Data Center, UNCTADstat: Geneva, Switzerland, 2019.

4. Lyridis, D.V.; Zacharioudakis, P.G. Liquid bulk shipping. The Black. Com. to Mari. Econ. 2012, $205-229$.

5. Stopford, M. Maritime Economics, 3rd ed.; Routledge: Oxford, UK, 2009.

6. Kavussanos, M.G. Price risk modelling of different size vessels in the tanker industry using autoregressive conditional heterskedastic (ARCH) models. Logist. Transp. Rev. 1996, 32, 161.

7. Glen, D.R.; Martin, B.T. A survey of the modelling of dry bulk and tanker markets. Res. Transp. Econ. 2005, 12, 19-64. [CrossRef]

8. Notteboom, T.E.; Vernimmen, B. The effect of high fuel costs on liner service configuration in container shipping. J. Transp. Geogr. 2009, 17, 325-337. [CrossRef]

9. Poulakidas, A.; Joutz, F. Exploring the link between oil prices and tanker rates. Marit. Policy Manag. 2009, 36, 215-233. [CrossRef]

10. El-Masry, A.A.; Olugbode, M.; Pointon, J. The exposure of shipping firms' stock returns to financial risks and oil prices: A global perspective. Marit. Policy Manag. 2010, 37, 453-473. [CrossRef]

11. UNCTAD. Oil Prices and Maritime Freight Rates: An Empirical Investigation; UNCTAD/DTL/TLB/2009/2; UNCTAD: Geneva, Switzerland, 2010. 
12. Shi, W.; Yang, Z.; Li, K.X. The impact of crude oil price on the tanker market. Marit. Policy Manag. 2013, 40, 309-322. [CrossRef]

13. Yang, Y.; Liu, C.; Sun, X.; Yang, J.L. Spillover effect of international crude oil market on tanker market. Int. J. Glob. Energy Issues 2015, 38, 257-277. [CrossRef]

14. Gavriilidis, K.; Kambouroudis, D.S.; Tsakou, K.; Tsouknidis, D.A. Volatility forecasting across tanker freight rates: The role of oil price shocks. Transp. Res. Part E Logist. Transp. Rev. 2018, 118, 376-391. [CrossRef]

15. Maitra, D.; Chandra, S.; Dash, S.R. Liner shipping industry and oil price volatility: Dynamic connectedness and portfolio diversification. Transp. Res. Part E Logist. Transp. Rev. 2020, 138, 101962. [CrossRef]

16. Siddiqui, A.W.; Basu, R. An empirical analysis of relationships between cyclical components of oil price and tanker freight rates. Energy 2020, 200, 117494. [CrossRef]

17. Michail, N.A.; Melas, K.D. Shipping markets in turmoil: An analysis of the Covid-19 outbreak and its implications. Transp. Res. Interdiscip. Perspect. 2020, 7, 100178. [CrossRef]

18. Angelopoulos, J.; Sahoo, S.; Visvikis, I.D. Commodity and transportation economic market interactions revisited: New evidence from a dynamic factor model. Transp. Res. Part E Logist. Transp. Rev. 2020, 133, 101836. [CrossRef]

19. Alizadeh, A.H.; Nomikos, N.K. Cost of carry, causality and arbitrage between oil futures and tanker freight markets. Transp. Res. Part E Logist. Transp. Rev. 2004, 40, 297-316. [CrossRef]

20. Zhang, Y. Investigating dependencies among oil price and tanker market variables by copula-based multivariate models. Energy 2018, 161, 435-446. [CrossRef]

21. Li, K.X.; Xiao, Y.; Chen, S.L.; Zhang, W.; Du, Y.; Shi, W. Dynamics and interdependencies among different shipping freight markets. Marit. Policy Manag. 2018, 45, 837-849. [CrossRef]

22. Bai, X.; Lam, J.S.L. A copula-GARCH approach for analyzing dynamic conditional dependency structure between liquefied petroleum gas freight rate, product price arbitrage and crude oil price. Energy Econ. 2019, 78, 412-427. [CrossRef]

23. Sun, X.; Liu, C.; Wang, J.; Li, J. Assessing the extreme risk spillovers of international commodities on maritime markets: A GARCH-Copula-CoVaR approach. Int. Rev. Financ. Anal. 2020, 68, 101453. [CrossRef]

24. Reboredo, J.C.; Ugolini, A. Downside/upside price spillovers between precious metals: A vine copula approach. N. Am. J. Econ. Financ. 2015, 34, 84-102. [CrossRef]

25. Jondeau, E. Asymmetry in tail dependence in equity portfolios. Comput. Stat. Data Anal. 2016, 100, 351-368. [CrossRef]

26. Patton, A.J. Modelling asymmetric exchange rate dependence. Int. Econ. Rev. 2006, 47, 527-556. [CrossRef]

27. Clarksons Research, Shipping Intelligence Weekly, No. 1224. 2016. Available online: https://www.crsl.com/ acatalog/shipping-intelligence-weekly.html (accessed on 15 August 2020).

28. Cleveland, R.B.; Cleveland, W.S.; McRae, J.E.; Terpenning, I. STL: A seasonal-trend decomposition. J. Off. Stat. 1990, 6, 3-73.

29. An, J.; Mikaylov, A. Russian energy projects in South Africa. J. Energy S. Afr. 2020, 31, 58-64. [CrossRef]

30. Yumashev, A.; Ślusarczyk, B.; Kondrashev, S.; Mikhaylov, A. Global indicators of sustainable development: Evaluation of the influence of the human development index on consumption and quality of energy. Energies 2020, 13, 2768. [CrossRef]

Publisher's Note: MDPI stays neutral with regard to jurisdictional claims in published maps and institutional affiliations.

(C) 2020 by the authors. Licensee MDPI, Basel, Switzerland. This article is an open access article distributed under the terms and conditions of the Creative Commons Attribution (CC BY) license (http://creativecommons.org/licenses/by/4.0/). 